\title{
Evaluation of Nevirapine Release Kinetics from Polycaprolactone Hybrids
}

\author{
Mariana S. S. B. Monteiro' ${ }^{*}$, Jackeline Lunz ${ }^{2}$, Pedro J. Sebastião3, Maria Inês Bruno Tavares ${ }^{2}$ \\ ${ }^{1}$ Faculdade de Farmácia, Universidade Federal do Rio de Janeiro, Centro de Ciências da Saúde, Bloco L, Cidade Universitária, Ilha do \\ Fundão, Rio de Janeiro, Brazil \\ ${ }^{2}$ Instituto de Macromoléculas Professora Eloísa Mano, Universidade Federal do Rio de Janeiro, Centro de Tecnologia, Bloco J, Cidade \\ Universitária, Ilha do Fundão, Rio de Janeiro, Brazil \\ ${ }^{3}$ Departamento de Física, Instituto Superior Técnico, Technical University of Lisbon, Lisbon, Portugal \\ Email: *marianasato@pharma.ufrj.br
}

How to cite this paper: Monteiro, M.S.S.B., Lunz, J., Sebastião, P.J. and Tavares, M.I.B. (2016) Evaluation of Nevirapine Release Kinetics from Polycaprolactone Hybrids. Materials Sciences and Applications, 7, 680701.

http://dx.doi.org/10.4236/msa.2016.711055

Received: September 7, 2016

Accepted: November 8, 2016

Published: November 11, 2016

Copyright $\odot 2016$ by authors and Scientific Research Publishing Inc. This work is licensed under the Creative Commons Attribution International License (CC BY 4.0).

http://creativecommons.org/licenses/by/4.0/

(c) (i) Open Access

\begin{abstract}
The Nevirapine (NVP)/Polycaprolactone (PCL)/Nanoparticles hybrids systems have been developed as a potential platform for drug delivery, by solvent cast, as thin films. NVP, an antiretroviral drug, was included within PCL matrix containing three types of nanoparticles: an organoclay layered silicate Viscogel $S 7^{\circ}(3 \% \mathrm{w} / \mathrm{w})$, hydrophilic silica oxide particles Aerosil ${ }^{\oplus}$ A20 $(0.25 \%$ w/w) and titanium dioxide particles $(0.25 \% \mathrm{w} / \mathrm{w})$. These systems were characterized by X-ray diffraction (XRD), Fourier-transform infrared spectroscopy (FTIR), low-field nuclear magnetic resonance (NMR), ultraviolet-visible spectroscopy (UV), in-vitro dissolution testing and drug release mechanism kinetics. The PCL crystallization was affected by NVP incorporation, modifying its semi-crystalline structure to a less ordered structure. When nanoparticles and NVP were added, the $\mathrm{T}_{1} \mathrm{H}$ values increased, for PCL, PCL/S7, PCL/ $\mathrm{SiO}_{2}$ and $\mathrm{PCL} / \mathrm{TiO}_{2}$ hybrids, suggesting that its addition produced a new material, with less molecular mobility, due to the new intermolecular interactions formation. It can consider a structure formation among the PCL chains, nanoparticles and NVP, with strong forces in the $\mathrm{PCL} / \mathrm{SiO}_{2} / \mathrm{NVP}$ system. The amount of NVP included was around $1.5 \pm 0.03 \mathrm{mg} / \mathrm{cm}^{2}$. In the in-vitro dissolution test, the $\mathrm{PCL} / \mathrm{SiO}_{2} / \mathrm{NVP}$ system released the smallest amount of drug and this result could be attributed to the strong intermolecular interaction between the drug and the $\mathrm{PCL} / \mathrm{SiO}_{2}$ system. Higuchi's model was the mathematical model chosen to treat the release data, since this model presented the highest coefficient correlation $(r)$ value. The drug release probably occur by diffusion through the matrix pores, thus, these materials are suitable for sustained release of NVP.
\end{abstract}

\section{Keywords}

Polycaprolactone, Nevirapine, Hybrids, Modified Release 


\section{Introduction}

The combination of organic and inorganic structures within a single material at nanoscopic level is one of the most effective approaches for producing new class of hybrids materials with advanced properties. A wide range of nanoparticles such as: clays, carbon nanotubes, graphites, polyhedral oligomeric silsesquioxane and metal oxides are currently available and used for prepared these systems [1]. These new compounds have been increasingly used in biomedical, pharmaceutical and cosmetics applications, presenting many advantages compared with individual polymers or other pharmaceutical excipients, such as: controlled drug release, targeted drug delivery, improved mechanical properties and stability [2] [3]. Furthermore, the effective dispersion and distribution of nanoparticles can modify the drug's release from the polymer matrix [4] [5].

In order to developed hybrids that can be used in pharmaceutical field, Polycaprolactone (PCL) was chosen, since it is a biopolymer. PCL is semicrystalline apliphatic polyester, considered as a biocompatible, and bioresorbable material with high permeability to drugs. Moreover PCL is approved by Food and Drug Administration (FDA) for biomedical applications. The PCL has a low glass-transition temperature of $-60^{\circ} \mathrm{C}$, a melting point of $60^{\circ} \mathrm{C}$, and exhibits high decomposition temperature around $350^{\circ} \mathrm{C}$. Compared to other biodegradable polyesters, the in vivo degradation of PCL is considerably long. This fact, added to its high permeability to drugs, favors its utilization in the design of long-term implant delivery devices, such as capronor ${ }^{\circledR}$ used to delivery levonorgestrel [6] [7] [8]. Other important fact is that the addition of nanofillers such as hydroxyapatite, clays, titanium oxide, graphite and silica has been reported as not affect the PCL bioactivity [9].

The clays are the most studied inorganic nanoparticles because of their abundance, price and well-known intercalation process. Depending on the interfacial interactions and mode of dispersion of the polymer and clay layers, three distinct morphologies can be obtained: unintercalated or microcomposite, intercalated or flocculated and exfoliated or delaminated [1]. Furthermore, clays nanoparticles have been highlighted in the pharmaceutical area, since they are widely used in conventional pharmaceutical dosage forms both as excipients and active agents. As excipient the mineral clay and their modified forms, like organoclay, can be effectively used to modify drug delivery system and control their release [10].

Titanium dioxide $\left(\mathrm{TiO}_{2}\right)$ nanoparticles are one of the most promising nanoparticles that are capable of being used in a wide variety of applications in medicine and life science. It is used in many products with industrial applications, such as paints, coatings, plastics, papers, inks, medicines, pharmaceuticals, food products, cosmetics, implants and toothphaste, because of their stability, low toxicity and photocatalytic properties. In the pharmaceutical field, $\mathrm{TiO}_{2}$ nanoparticles are being used in various skin care products, like aerosols, suspensions or emulsions [11]. $\mathrm{TiO}_{2}$ based drug delivery system can successfully improve efficiency of drug delivery by prolonging exposure time to drugs, by enhancing local concentrations of drugs and by reducing drug's toxic- 
ity in normal cell [12].

Amorphous silica $\left(\mathrm{SiO}_{2}\right)$ nanoparticles are non-toxic and regularly used as food additives, components of vitamin supplements, dental roots and bone regenerative materials. Encapsulation in silica has also been found to prolong the shelf life of enzymes. Bacteria and mammalian cells have been shown to retain their metabolic activities when encapsulating in porous silica, confirming the high compatibility of silica with biological system. Their intrinsic hydrophilicity and biocompatibility makes then perfect candidates for controlled drug-delivery applications [13] [14]. However, all of these intrinsic advantages, there is a relative difficulty of manipulating the silica nanoparticles.

Despite nanocomposites possess several advantages, its limitations should also be mentioned, including the difficulty of nanofillers dispersion, its sedimentation, processability and the use of organic solvent. Consequently, all these parameters can affect the drug distribution in the nanocomposite matrix, interfering with its release. Hence, further research is required for a better understanding of formulations/structure/property relationships.

Acquired immunodeficiency syndrome (AIDS) seems to be one of the most devastating epidemics with 40 million people presently infected with human immunodeficiency virus type 1 (HIV-1) globally. An effective therapy for AIDS treatment includes highly active antiretroviral therapy which involves the combination of three or four antiretroviral drugs. However, the first pass metabolism and degradation of antiretroviral drugs in the gastrointestinal tract results in poor bioavailability and patient incompliance. So, it is desirable to have a controlled or sustained release drugs delivery system that could improve patient compliance, reduce the side effects and increase the therapeutic efficacy [15].

Nevirapine (NVP) is an excellent choice for the treatment of AIDS since it is a nonnucleoside reverse transcriptase inhibitor of human immunodeficiency virus type 1 (HIV-1), blocks polymerase activity after binding directly to the HIV-1 reverse transcriptase, leading to the disruption of the enzyme's catalytic site [16] [17]. Moreover, it is the most prescribed inhibitor of HIV-1 in the world and remains the most prescribed antiretroviral in countries with limited economic resources. However, NVP use has been associated with severe side effects that include hepatotoxicity, insomnia, confusion, memory loss, depression, rashes, nausea, dizziness, toxic epidermal necrolysis and hyperlipidemia [18]. An alternative to enhance the clinical potential of NVP is the development of a drug delivery system that can assist in its sustained and target delivery [15].

In this context, this work developed and characterized a promising pharmaceutical system which consists in a nanostructure material containing f PCL, Viscogel S7, an organo modified clay, titanium dioxide nanoparticles and silica amorphous nanoparticles, by solvent cast, in order to produce a NVP controlled drug delivery system. The systems developed were characterized by X-ray diffraction (XRD), Fourier-transform infrared spectroscopy (FTIR), low-field nuclear magnetic resonance (NMR), UV-Vis spectroscopy (UV) and the in-vitro dissolution test. An additional aim of this work was 
to evaluate drug release data using various kinetic models and to determine the drug release mechanism.

\section{Materials and Methods}

\subsection{Materials}

Polycaprolactone (PCL) pellets (Mw: 80,000 - 100,000 $\mathrm{g} / \mathrm{mol}^{-1}$ ) obtained from Sigma Aldrich, was used as the polymer matrix. The organoclay Viscogel S7, containing the dimethyl benzyl hydrogenated tallow ammonium group as a modifier, was obtained from Bentec-Laviosa Chimica Mineraria (Italy). This clay is based on mineral clay named montmorillonite, which is a sodium aluminum hydrosilicate, morphologically constituted of alumina octahedrons sandwiched between two layers of silica tetrahedrons. The layer thickness is around $1 \mathrm{~nm}$ and specific surface area of $800 \mathrm{~m}^{2} / \mathrm{g}$. Hydrophilic silica oxide particles $\left(\mathrm{SiO}_{2}\right)$ were supplied by Evonik (Brazil), Aerosil ${ }^{\circledR}$ A200, with a specific surface area of $170 \mathrm{mg}^{2} / \mathrm{g}$ with an average primary particle size of $12 \mathrm{~nm}$. Titanium dioxide particles $\left(\mathrm{TiO}_{2}\right)$ were supplied by DuPont (Brazil), having specific surface area of $50 \mathrm{mg}^{2} / \mathrm{g}$ and average primary particle size of $25 \mathrm{~nm}$. Nevirapine (NVP) was supplied by Oswaldo Cruz Foundation (Rio de Janeiro, Brazil). Chloroform was purchased from TediaBrazil. All materials were used without further modification.

\subsection{Preparation of Hybrids}

The PCL film was produced using a solvent casting technique. Briefly, the PCL granules were dissolved in chloroform at room temperature overnight with vigorous stirring to obtain a concentration of $5 \% \mathrm{w} / \mathrm{v}$. The solution was poured into a glass Petri dish, which was covered and placed at room temperature for slow evaporation. The dried film was collected and vacuum dried for $48 \mathrm{~h}$. Chloroform was chosen as solvent according to the PCL solubility parameter, obtained in a previous study.

The PCL/clay hybrids were also prepared through the solvent casting technique, using chloroform as the solvent. The solutions of PCL and organoclay were added in a flat-bottom insulated flask. The flasks with the isolated solutions were sealed and stirred at room temperature for $24 \mathrm{~h}$. After that, the solutions were mixed and left for $24 \mathrm{~h}$ under stirring. The resulting mixture was poured into Petri dishes and kept at room temperature. The hybrids films were further dried under vacuum for $48 \mathrm{~h}$ and all the samples were stored in desiccators until use. Films with 3\% w/w of Viscogel S7 clay were obtained. The same procedure was performed for the titanium and silica dioxide particles, but the final concentration of both particles in each system was $0.25 \% \mathrm{w} / \mathrm{w}$ [19] [20] [21] [22].

The NVP was added to the PCL by dissolving it in a small amount of chloroform and then stirring the solution for $30 \mathrm{~min}$ before pouring into a glass Petri dish. The amount of NVP in each system was $10 \% \mathrm{w} / \mathrm{w}$ in relation to the PCL.

In our previous study, the thermogravimetric analysis was used to determine the percentage of nanoparticles incorporated in the PCL film and the following weight fraction were found: $3.07 \% \mathrm{w} / \mathrm{w}$ of Viscogel S7 clay, $0.23 \% \mathrm{w} / \mathrm{w}$ of titanium dioxide 
particles and 0.29\% w/w of Aerosil ${ }^{\circledR}$ A200 [19] [20].

\subsection{X-Ray Diffraction}

The crystalline structure of the PCL and PCL/NVP hybrids were investigated by X-ray diffraction (XRD) using a Rigaku D/Max 2400 diffractometer, with nickel-filtered CuKa radiation of wavelength $1.54 \AA$, at room temperature. The $2 \theta$ scanning range was varied from $2^{\circ}$ to $30^{\circ}$, with $0.02^{\circ}$ steps, operated at $40 \mathrm{KV}$ and $30 \mathrm{~mA}$. The degree of crystallinity of the samples was calculated from the integrated area of X-ray diffraction data, using the Fytik software, for which were assumed Gaussian profiles for crystalline and amorphous peaks. The areas under the crystalline and amorphous phase were determined in arbitrary units and the degree of crystallinity $\left(X_{c}\right)$ and amorphous content $\left(X_{a}\right)$ were obtained using the following relationship (Expression 1) [21] [23]:

$$
X_{c}=\frac{I_{c}}{I_{a}+I_{c}}, X_{a}=\frac{I_{a}}{I_{a}+I_{c}}
$$

where $I_{a}$ and $I_{c}$ are the integrated intensities corresponding to the crystalline and amorphous phases, respectively.

\subsection{NMR Relaxation Method}

Proton Spin-lattice relaxation time $\left(\mathrm{T}_{1} \mathrm{H}\right)$

The proton spin-lattice relaxation time in the laboratory frame is also known as longitudinal relaxation, possesses a time constant $\mathrm{T} 1$ and the mechanism of this relaxation process occurs in the $z$-direction. T1 relaxation corresponds to the process of establishing $\mathrm{z}$ component of the nuclear spin magnetization to its thermal equilibrium.

A Maran Ultra 23 low-field NMR spectrometer (Oxford Instruments), operating at $23 \mathrm{MHz}$ (for protons) and equipped with an $18 \mathrm{~mm}$ NMR tube was used to determine proton spin-lattice relaxation times $\left(\mathrm{T}_{1} \mathrm{H}\right)$. The pulse sequence used was inversion-recovery (recycle delay- $180^{\circ}-\tau-90^{\circ}$ acquisition data) and the $90^{\circ}$ pulse of $4.6 \mu$ s was calibrated automatically by the software supplied with the instrument. The amplitude of the FID was sampled for $20 \tau$ data points, ranging from 0.1 to $100.000 \mathrm{~ms}$, using 40 data points with 4 scans for each point and $5 \mathrm{~s}$ of recycle delay. The relaxation values were obtained by fitting the exponential data with the aid of the WINFIT program, and the domain distribution was obtained by the WINDXP software. The equipment's precision is $\pm 2 \%$. The relaxation values were calculated employing the following equation (Expression 2). The temperature of the analysis was $25^{\circ} \mathrm{C}$ [19] [20].

$$
\mathrm{Mo}=\mathrm{Mz}\left(1-\exp ^{-\tau / T 1}\right)
$$

where, Mo is a equilibrium value, $\mathrm{Mz}$ is a time period during which spin-lattice relaxation occurs causing $\mathrm{Mz}$ to go from value of - Mo through zero to its equilibrium value of Mo, $\tau$ is time period delay and $\mathrm{T} 1$ is a spin-lattice relaxation time.

\subsection{FTIR Analysis}

FTIR was employed to characterize the possible interaction between the drug and the 
hybrids in a Varian Excalibur, model 3100 FTIR spectrometer. The spectra were scanned over a frequency range of $4000-400 \mathrm{~cm}^{-1}$, at room temperature, using 64 scans and with resolution of $4 \mathrm{~cm}^{-1}$. The samples were investigated by film form [24].

\subsection{Drug Content}

The amount of NVP included in the hybrid systems was determined using UV-Visible spectroscopy in a Varian Cary 100 Conc spectrometer, at $\lambda=313 \mathrm{~nm}$. The polymeric/ NVP films were divided in small pieces with $2 \times 2 \mathrm{~cm}^{2}$, diluted in $100 \mathrm{~mL}$ of chloroform and analyzed by UV spectroscopy. The systems were analyzed in triplicate. Also, the hybrid systems without drug were analyzed using the same conditions, to ensure the specificity of the method [25].

\subsection{In Vitro Dissolution Studies}

The drug dissolution studies were carried out using the USP I dissolution apparatus (basket) with $80 \mathrm{rpm}$ rotational speed. The dissolution test was conducted at $37^{\circ} \mathrm{C} \pm$ $0.5^{\circ} \mathrm{C}$ in $900 \mathrm{~mL}$ of $0.1 \mathrm{~N} \mathrm{HCl}$ solution, $\mathrm{pH}=1.2 \pm 0.1$, using a Nova Ética dissolution test station (Brazil), model 299, containing three vessels. Three pieces of PCL films, having the $2 \times 2 \mathrm{~cm}^{2}$ dimensions, were placed in each basket. To determine the amount of drug dissolved, $4 \mathrm{~mL}$ of the samples were collected at $0,15,30,45,60,120$ and 180 minute intervals. Fresh solution was added after each sample withdrawal. Each time the volume of aliquots was replaced with the fresh dialyzing medium. Sample solutions were measured comparatively to reference calibration curve for NVP at $\lambda 313 \mathrm{~nm}$, using the respective dissolution medium as a blank. The tests were performed in triplicate and the dissolution data were presented as mean \pm standard deviation. The desired sink condition was maintained for the studies [26].

The $0.1 \mathrm{~N} \mathrm{HCl}$ solution was chosen as the media for NVP dissolution studies once the maximum dissolution, i.e. more than $80 \%$ release, was found in this media. The drug is weakly basic and exhibits $\mathrm{pH}$ dependent solubility [27]. Furthermore, $0.1 \mathrm{~N}$ HCL media resembles a gastric environment.

\subsection{Data Analysis}

To analyze the in vitro release data, various models were used to describe the release kinetics. The zero-order rate of Equation (1) describes those systems where the drug release rate is independent of its concentration. The first-order rate of Equation (2) describes the release from a system where the release rate is concentration dependent. Higuchi (1963) described the release of drugs from insoluble matrixes as a square root of a time-dependent process based on Fickian diffusion, as per Equation (3). The Hixson-Crowell cube root law, according to Equation (4), describes the release from a system where there is a change in surface area and diameter of particles or tablets [28] [29].

$$
C=C_{0}-k_{0} t
$$

where, $C$ is the amount of drug released or dissolved, $C_{0}$ is the initial amount of drug in 
solution, $k_{0}$ is the zero-order rate constant, expressed in units of concentration/time, and $t$ is the time. For the study of release kinetics, the graph is plotted between cumulative amount of drug released verses time.

$$
\log C=\log C_{0}-k t / 2.303
$$

where, $C_{0}$ is the initial concentration of drug, $k$ is the first-order constant and $t$ is the time. The data obtained are plotted as log cumulative percentage drug remaining verses time, which yield a straight line with slop $=k / 2.303$

$$
C=[D(2 q t-C s) C s t]^{1 / 2}
$$

where, $C$ is the total amount of drug release per unit area of the matrix $\left(\mathrm{mg} / \mathrm{cm}^{2}\right), D$ is the diffusion coefficient for the drug in the matrix $\left(\mathrm{cm}^{2} / \mathrm{hr}\right), q t$ is the total amount of drug in a unit volume matrix $\left(\mathrm{mg} / \mathrm{cm}^{3}\right), C s$ is the dimensional solubility of the drug in the polymer matrix $\left(\mathrm{mg} / \mathrm{cm}^{3}\right), t$ is the time $(\mathrm{hr})$. Data obtained are plotted as cumulative percentage of drug release verses square root of time.

$$
C_{0}^{1 / 3}-C t^{1 / 3}=K_{H C} t
$$

where, $C t$ is the amount of drug released in time $t, C_{0}$ is the initial amount of the drug in tablet, $K_{H C}$ is the rate constant for Hixson-Crowell equation and $t$ is the time. Plot made in between cube root of drug percentage remaining in matrix verses time.

\subsection{Statistics}

Experimental data are presented as mean \pm standard deviation. Statistical analysis was performed using the one-way analysis of variance test (Tukey's multiple comparisons) with Origin ${ }^{\oplus}$ Pro 8 software. $\mathrm{P}>0.05$ was considered statistically significant.

\section{Results and Discussion}

\subsection{XRD Measurements}

The XRD technique was used to identify, characterize and calculate the crystallinity index of the hybrids. The XRD patterns of NVP, PCL, Viscogel S7 clay, $\mathrm{SiO}_{2}$ nanoparticles, $\mathrm{TiO}_{2}$ nanoparticles, $\mathrm{PCL} / \mathrm{S} 7$ hybrid, $\mathrm{PCL} / \mathrm{SiO}_{2}$ hybrid, $\mathrm{PCL} / \mathrm{TiO}_{2}$ hybrid, PCL/ NVP $10 \%$ w/w hybrid, PCL/S7/NVP 10\% w/w hybrid, PCL/SiO $/ 2$ NVP $10 \%$ w/w hybrid and $\mathrm{PCL} / \mathrm{TiO}_{2} / \mathrm{NVP} 10 \% \mathrm{w} / \mathrm{w}$ hybrid are shown in Figure 1.

There are two distinct peaks, observed at $2 \theta=21.6^{\circ}$ and $2 \theta=23.8^{\circ}$, in the diffractogram (Figure 1), which are indexed to be (110) and (200) planes, respectively, of an orthorhombic crystalline structure of PCL [30] [31]. The XRD trace of NVP displays intense and sharp diffraction peaks at $2 \theta=9.5^{\circ}, 13.1^{\circ}$ and $25.5^{\circ}$, indicating its crystalline structure [17]. The PCL/NVP $10 \% \mathrm{w} / \mathrm{w}$ sample presented the same peaks at $2 \theta=$ $21.4^{\circ}$ and $23.8^{\circ}$, suggesting that the crystallization of PCL was not affect by the addition of NVP, in this system without nanoparticles. The disappearance of all NVP crystal peaks indicates the NVP crystallinity was reduced, when the drug is embedded inside the hybrid matrix, indicating an amorphous dispersion of NVP in the PCL matrix [21] [32]. 


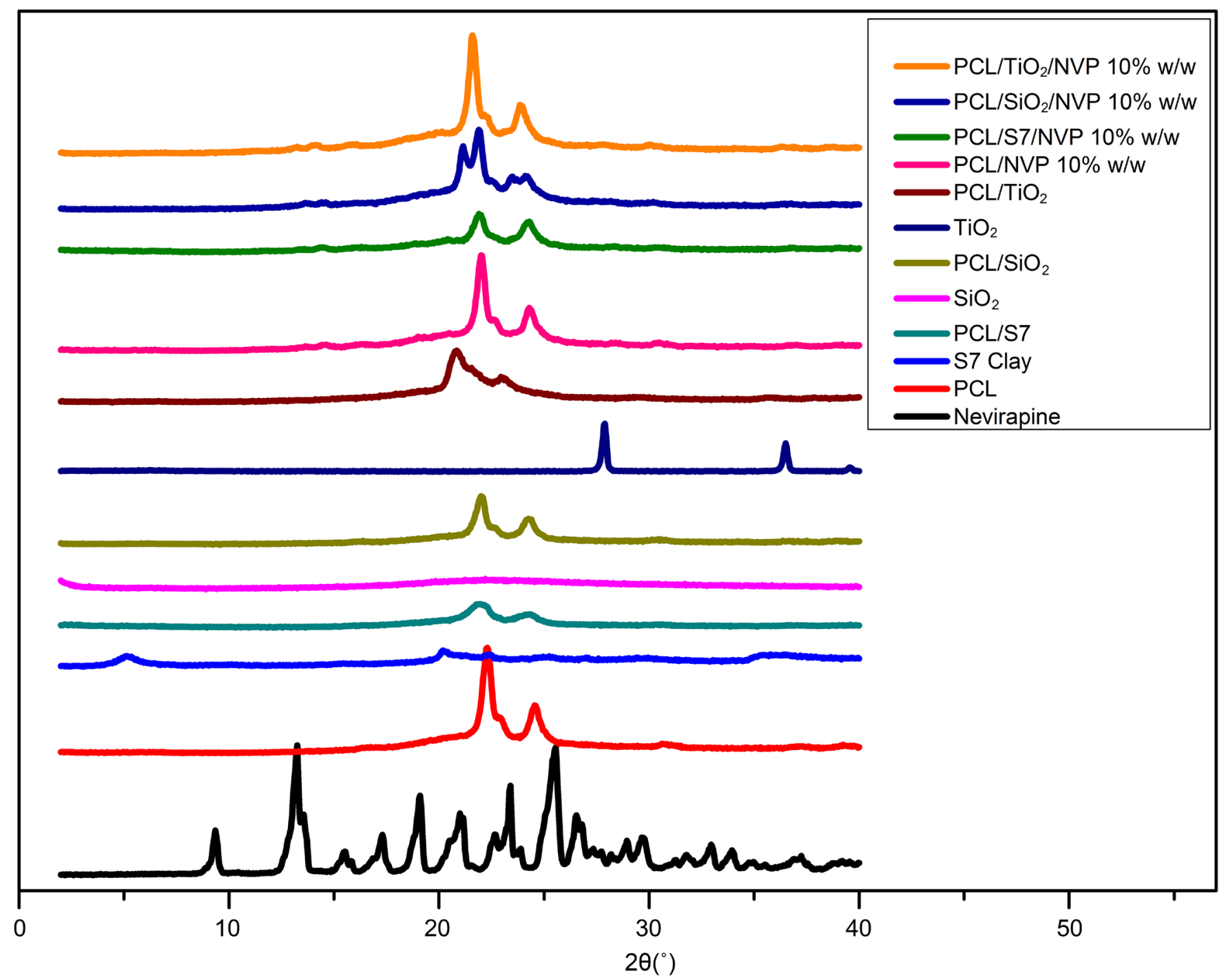

Figure 1. XRD curves of NVP, PCL, Viscogel S7 clay, $\mathrm{SiO}_{2}$ nanoparticles, $\mathrm{TiO}_{2}$ nanoparticles, $\mathrm{PCL} / \mathrm{Viscogel} \mathrm{S7,} \mathrm{PCL} / \mathrm{SiO}{ }_{2}, \mathrm{PCL} / \mathrm{TiO}$, PCL/NVP 10\% w/w, PCL/Viscogel S7/NVP 10\% w/w, PCL/SiO $/ 2$ NVP 10\% w/w and PCL/TiO $/ \mathrm{NVP} 10 \%$ w/w hybrid systems.

According the Figure 1, the XRD pattern for the Viscogel S7 organoclay presents a reflection at about $2 \theta=5.14^{\circ}$, corresponding to a basal spacing of $17.19 \AA$, and an almost imperceptible reflection for the PCL/Viscogel S7 hybrids, demonstrating disordering in this clay's layers. Additionally, in our previous work it was confirmed that an intercalated nanocomposite was achieved [19]. The addition of NVP caused a major decrease in PCL crystalline peaks, suggesting that PCL crystallization was affected by the NVP inclusion, when clay nanoparticles were also present in the system. The disappearance of all NVP crystal peaks indicates the NVP crystallinity was reduced, when the drug is embedded inside the hybrid matrix and indicating an amorphous dispersion of NVP [21] [32].

Figure 1 also shows the XRD curves of the PCL/Aerosil ${ }^{\circledR}$ A200 hybrid materials developed. The X-ray diffraction showed that silica oxide nanoparticles are predominantly 
amorphous [33]. The crystalline peaks, attributed to the crystallographic planes of the PCL crystal, $2 \theta=21.4^{\circ}$ and $23.8^{\circ}$, remained after the $\mathrm{SiO}_{2}$ incorporation, indicating that the polymer crystalline structure did not change [20] [34]. Beyond that a new peak appears for $\mathrm{PCL} / \mathrm{SiO}_{2} / \mathrm{NVP}$ compares with the curve for $\mathrm{PCL} / \mathrm{SiO}_{2}$, which may be an indicative of a change in the pattern of NVP dispersion in this hybrid system, containing silica nanoparticles. Also the disappearance of all NVP crystal peaks indicates the NVP crystallinity was reduced, when the drug is embedded inside the hybrid matrix, indicating an amorphous dispersion of NVP [21] [32].

Figure 1 also presents the XRD curves of the $\mathrm{PCL} / \mathrm{TiO}_{2}$ hybrid materials. The introduction of a small amount of $\mathrm{TiO}_{2}$ modified the PCL crystalline structure, as can be seen through the decrease of PCL crystalline peaks [35]. Therefore, the addition of NVP $10 \% \mathrm{w} / \mathrm{w}$ caused some modifications in the crystalline structure, offsetting the $\mathrm{TiO}_{2}$ introduction. That result can be confirmed by the increase of the PCL crystalline peaks in the $\mathrm{PCL} / \mathrm{TiO}_{2} / \mathrm{NVP}$ hybrids. Also the disappearance of all NVP crystal peaks indicates the NVP crystallinity was reduced, when the drug is embedded inside the hybrid matrix, indicating an amorphous dispersion of NVP [21] [32].

The crystallinity of all hybrids developed was obtained by curve fitting to calculate the area of each peak. Linear background correction was applied separately to the observed peaks before obtain the area under each peak, for which it was assumed a Gaussian profile. The PCL crystallinity values are shown in Table 1.

Table 1 shows that the incorporation of nanoparticles and NVP decreased the PCL crystallinity in all hybrid systems, compared to pure PCL. The nanoparticles introduction decreased the PCL crystallinity in all hybrids systems, the PCL/S7, PCL/SiO $\mathrm{Si}_{2}$ and $\mathrm{PCL} / \mathrm{TiO}_{2}$ showed a crystalline value of $39 \%, 44 \%$ and $42 \%$, respectively (Table 1 ). In our previous study, the hybrids crystallinity was evaluated by differential scanning calorimetry analysis, and the hybrids $\mathrm{PCL} / \mathrm{S} 7, \mathrm{PCL} / \mathrm{SiO}_{2}$ and $\mathrm{PCL} / \mathrm{TiO}_{2}$ presented the following crystallinity values $39.4 \%, 42.86 \%$ and $41.72 \%$ [19] [20] [21]. Thus, the results are very similar, indicating that both methods can be used to calculate the crystallinity of hybrids systems. Probably, the nanoparticles hindered the PCL crystallization, leading to some changes in the semi-crystalline PCL structure, resulting to a less ordered compound.

Table 1. Crystalline values for PCL and PCL hybrids.

\begin{tabular}{cc}
\hline Samples & $X_{c}(\%)$ \\
\hline PCL & 53 \\
PCL/NVP $10 \% \mathrm{w} / \mathrm{w}$ & 40 \\
PCL/S7 & 39 \\
$\mathrm{PCL} / \mathrm{S} 7 / \mathrm{NVP} 10 \% \mathrm{w} / \mathrm{w}$ & 36 \\
$\mathrm{PCL} / \mathrm{SiO}_{2}$ & 44 \\
$\mathrm{PCL} / \mathrm{SiO}_{2} / \mathrm{NVP} 10 \% \mathrm{w} / \mathrm{w}$ & 50 \\
$\mathrm{PCL} / \mathrm{TiO}_{2}$ & 42 \\
$\mathrm{PCL} / \mathrm{TiO}_{2} / \mathrm{NVP} 10 \% \mathrm{w} / \mathrm{w}$ & 35 \\
\hline
\end{tabular}


When the NVP was introduced in the PCL, PCL/S7 and PCL/TiO ${ }_{2}$ hybrids systems showed a major reduction in the PCL crystalline degree, as can be seen in Table 1 . The $\mathrm{PCL} / \mathrm{NVP}, \mathrm{PCL} / \mathrm{S} 7 / \mathrm{NVP}$ and $\mathrm{PCL} / \mathrm{TiO}_{2} / \mathrm{NVP}$ presented a crystalline value of $40 \%, 36 \%$ and $35 \%$. These values are lower than those of hybrids without the NVP, consequently the concomitant introduction of nanoparticles and NVP promoted a synergistic effect, leading to some changes in the semi-crystalline PCL structure, resulting to a less ordered compound and reducing the PCL crystallinity. A possible explanation is the hydrogen bond and the electrostatic interaction between PCL and NVP [21] [32]. However, in the $\mathrm{PCL} / \mathrm{SiO}_{2} / \mathrm{NVP}$ system, the drug incorporation did not increase the PCL crystallinity if compared with its original data; instead the drug incorporation appears to increase the crystallinity of $\mathrm{PCL} / \mathrm{SiO}_{2}$ system, and in part reversed the clay effect in the PCL crystallinity.

\subsection{NMR Relaxation Analysis}

The solid state NMR was used to evaluate the median behavior of the samples, because the time scale of the measurements is at the molecular level and the domains detected have sizes, which vary from 25 to $50 \mathrm{~nm}$. According to the main purpose of this work, hydrogen spin-lattice relaxation time measurements were recorded to get more information on the samples homogeneity, nanoparticles dispersion, drug dispersion and the interaction process in the hybrids [19] [20]. Table 2 shows the $\mathrm{T}_{1} \mathrm{H}$ values and Figure 2 shows the $\mathrm{T}_{1} \mathrm{H}$ curves for the PCL chain, PCL/hybrids and PCL/NVP/hybrids developed, determined by low-field NMR.

Table 2 shows that the $\mathrm{T}_{1} \mathrm{H}$ values of PCL film was $95 \mathrm{~ms}$, PCL/S7 hybrid was $102 \mathrm{~ms}$, $\mathrm{PCL} / \mathrm{SiO}_{2}$ hybrid was $98 \mathrm{~ms}$ and $\mathrm{PCL} / \mathrm{TiO}_{2}$ hybrid was $96 \mathrm{~ms}$. Then, when the nanoparticles were added, the $\mathrm{T}_{1} \mathrm{H}$ value increased, suggesting that its addition produced a material, with less molecular mobility, when compared to the PCL film. Presumably, the new material presets new stronger interactions, caused by the molecular rearrangement of the nanoparticles in the PCL chains. The NVP introduction in the hybrids systems increased in the $\mathrm{T}_{1} \mathrm{H}$ values for $\mathrm{PCL}, \mathrm{PCL} / \mathrm{SiO}_{2}$ and $\mathrm{PCL} / \mathrm{TiO}_{2}$ hybrids systems. Thus

Table 2. Proton spin-lattice relaxation times of PCL, PCL hybrids and PCL hybrids with NVP $10 \% \mathrm{w} / \mathrm{v}$, determined by low-field NMR, employing lexponential value with $2 \%$ error.

\begin{tabular}{cc}
\hline Sample & $\mathrm{T}_{1} \mathrm{H}_{\text {one Exp }}(\mathrm{ms}) \pm 2 \%$ error \\
\hline $\mathrm{PCL}$ & 95 \\
$\mathrm{PCL} / \mathrm{NVP} 10 \% \mathrm{w} / \mathrm{w}$ & 99 \\
$\mathrm{PCL} / \mathrm{S} 7$ & 102 \\
$\mathrm{PCL} / \mathrm{S} 7 / \mathrm{NVP} 10 \% \mathrm{w} / \mathrm{w}$ & 93 \\
$\mathrm{PCL} / \mathrm{SiO}_{2}$ & 98 \\
$\mathrm{PCL} / \mathrm{SiO}_{2} / \mathrm{NVP} 10 \% \mathrm{w} / \mathrm{w}$ & 104 \\
$\mathrm{PCL}_{\mathrm{TiO}}$ & 96 \\
$\mathrm{PCL} / \mathrm{TiO}_{2} / \mathrm{NVP} 10 \% \mathrm{w} / \mathrm{w}$ & 98 \\
\hline
\end{tabular}




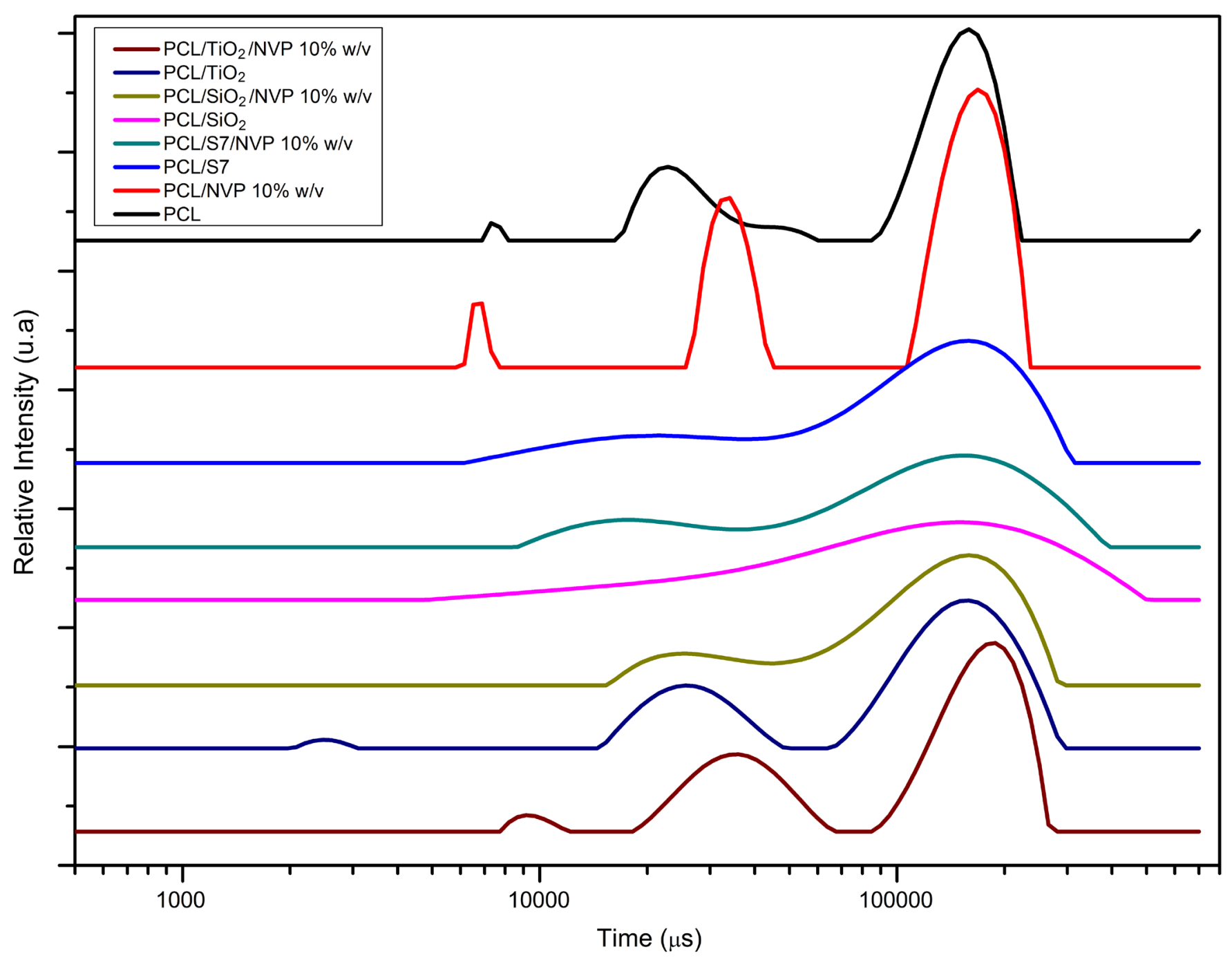

Figure 2. Distribution curves obtained by low-Field NMR of PCL, PCL hybrids and PCL hybrids with NVP.

the drug introduction, further reduced the PCL molecular mobility, and generated a material with less molecular mobility. However, the NVP introduction decreased the $\mathrm{T}_{1} \mathrm{H}$ value in the PCL/S7 system, so in clay system the NVP increased the PCL molecular mobility, compensating the effect of clay introduction [21] [22].

Figure 2 shows the domain distribution curves of proton spin-lattice relaxation times obtained for PCL hybrids. The PCL film showed the presence of three well defined domains, indicating three distinct environments: i) rigid crystallites, which are more organized with slower and more restricts chain motions, presenting higher $\mathrm{T}_{1} \mathrm{H}$ values, ii) a "rigid amorphous" region, where PCL chains have intermediate mobility, presenting intermediate $\mathrm{T}_{1} \mathrm{H}$ values and iii) a flexible-amorphous region, where PCL chains are more mobile with move faster, thus presenting shorter $\mathrm{T}_{1} \mathrm{H}$ [21]. When the NVP was incorporated in the PCL matrix, there was a small shift in the flexible amorphous domain, indicating that the NVP molecules were better distributed in the flexible-amorphous part of PCL, as can be seen in Figure 3. 


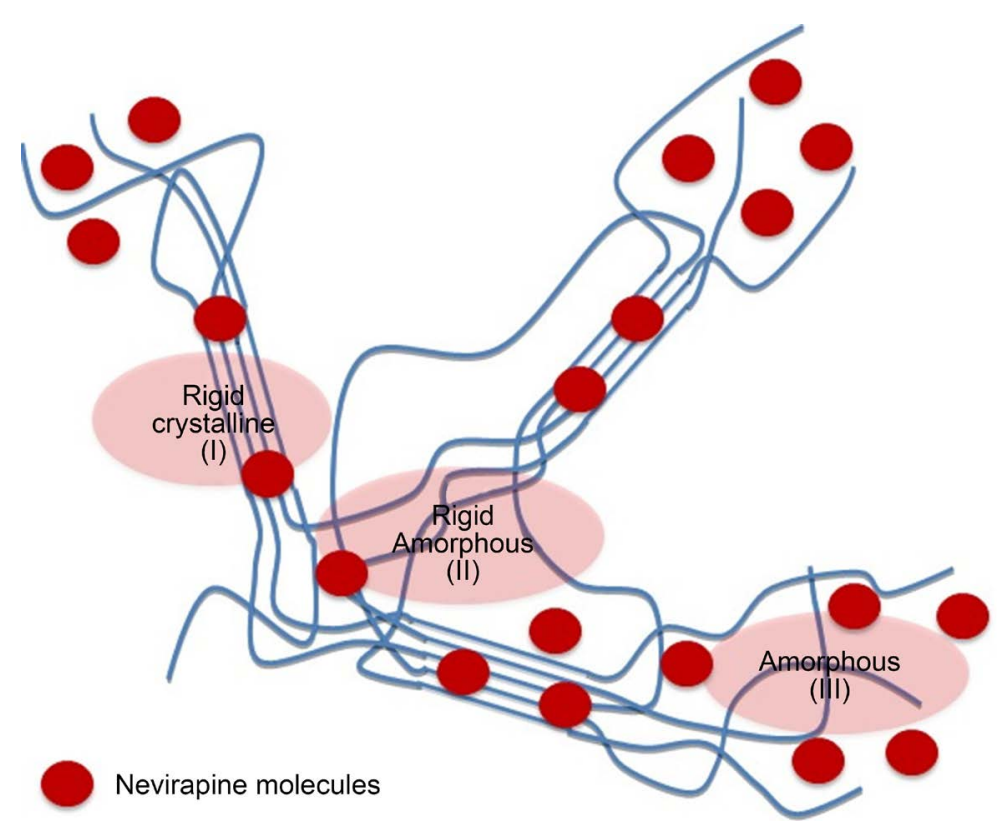

Figure 3. Scheme of PCL/NVP system.

The introduction of clay and silica nanoparticles showed a bimodal effect on the domain curves for the PCL/S7 and $\mathrm{PCL} / \mathrm{SiO}_{2}$ hybrids, and the suppressing of flexible amorphous domains. Furthermore, the addition of these nanoparticles caused a modification in the rigid crystallite domains and in the rigid amorphous domains, as can be seen from the two areas wider than the base material. Thus, the addition of clay and silica has generated a more heterogeneous material, which can be evidenced by the formation of new domains with different molecular motions. The introduction of $\mathrm{TiO}_{2}$ nanoparticles, in the PCL matrix, also showed three well defined domains, very similar to the PCL. Therefore, the introduction of $\mathrm{TiO}_{2}$ nanoparticles did not alter the molecular dynamics of PCL.

The NVP insertion in the PCL/S7 hybrid system presented a monomodal effect in the domain curve. Also there was the suppressing of the flexible amorphous domain and a modification in the rigid crystallite domain and in the rigid amorphous domain, as can be seen from the area wider than the base material, indicating one environment. Thus, the NVP molecules can modify the polymer arrangement around the S7 clay. In the $\mathrm{PCL} / \mathrm{SiO}_{2}$ hybrid, the NVP introduction did not change the bimodal effect in the domain curve, indicating that the drug had less influence on the hybrid dynamics. The $\mathrm{PCL} / \mathrm{TiO}_{2} / \mathrm{NVP}$ hybrid also presented three well defined domains, very similar to the PCL pattern, however, a slight enlargement can be seen in the "rigid-amorphous" domain, suggesting a NVP dispersion in this domain.

In our previous study, PCL hybrids containing layered silicates, silica and dioxide titanium, with NVP, were characterized by proton nuclear magnetic resonance relaxometry, in the Larmor frequency range, between $10 \mathrm{kHz}$ and $300 \mathrm{MHz}$, to obtain information about the molecular motions in different time scales. The magnetization decay behavior for PCL was described by a triexponential behavior, characterized by three 
spin-lattice relaxation times, in the frequency range from around $300 \mathrm{kHz}$ to $300 \mathrm{MHz}$. This behavior was associated with a decoupling of spin lattice relaxation between three proton subsystems: rigid-crystallite, rigid-amorphous and flexible-amorphous region [21] [22].

Since the proton spin-lattice relaxation times depends on the dipolar interactions between intra- or inter-molecular hydrogen proton spins modulated by molecular motions, it provides information about the molecular mobility of polymer chains. Consequently, this technique can be used to study the phase composition based on the heterogeneities of molecular mobility in polymer [22].

Thus, the analysis performed in the NMR spectrometer at $23 \mathrm{MHz}$, in this work, confirmed the results of our previous study. Where, PCL and their hybrids showed three different relaxation times, which can be correlated with different motilities of PCL protons molecular chains.

\subsection{FTIR Analyses}

The chemical structure and interactions between the hybrid components were identified by FTIR. Figure 4 shows the FTIR spectra of NVP, PCL, PCL/NVP 10\% w/w, $\mathrm{PCL} / \mathrm{Viscogel} \mathrm{S} 7 / \mathrm{NVP} 10 \% \mathrm{w} / \mathrm{w}, \mathrm{PCL} / \mathrm{SiO}_{2} / \mathrm{NVP} 10 \% \mathrm{w} / \mathrm{w}$ and $\mathrm{PCL} / \mathrm{TiO}_{2} / \mathrm{NVP} 10 \%$ $\mathrm{w} / \mathrm{w}$. The PCL spectrum display characteristics peaks of $\mathrm{C}=\mathrm{O}$ stretching vibrations at $1725 \mathrm{~cm}^{-1}, \mathrm{CH}_{2}$ symmetric stretching at $2862 \mathrm{~cm}^{-1}$ and $\mathrm{CH}_{2}$ asymmetric stretching 2945 $\mathrm{cm}^{-1}$, and the C-O-C stretching vibrations peaks at $1042 \mathrm{~cm}^{-1}, 1166 \mathrm{~cm}^{-1}$ and $1220 \mathrm{~cm}^{-1}$ [24].

All the systems showed absorption peaks at about $2862 \mathrm{~cm}^{-1}$ and $2945 \mathrm{~cm}^{-1}$, which are attributed to the symmetric and asymmetric stretching vibrations of the $\mathrm{CH}_{2}$ group of PCL [24]. Also, all the systems showed peaks at about $1722 \mathrm{~cm}^{-1}, 1166 \mathrm{~cm}^{-1}$ and 731 $\mathrm{cm}^{-1}$. The strong peak at $1722 \mathrm{~cm}^{-1}$ can be attributed to the PCL carbonyl stretching. The peak at about $1166 \mathrm{~cm}^{-1}$ can be attributed to the symmetric stretching of the O-C-O group of PCL [36] [37].

Moreover, all the system presented small peaks at $1647 \mathrm{~cm}^{-1}, 1467 \mathrm{~cm}^{-1}, 1421 \mathrm{~cm}^{-1}$, $1290 \mathrm{~cm}^{-1}, 1242 \mathrm{~cm}^{-1}, 610 \mathrm{~cm}^{-1}$. The peaks at about $1420 \mathrm{~cm}^{-1}$ are related to the strain of $\mathrm{CH}_{2}$ group in the NVP propyl ring, the peaks between $1210 \mathrm{~cm}^{-1}$ and $1300 \mathrm{~cm}^{-1}$ are related to the strain stretching of $\mathrm{CH}$ groups of both NVP rings. So the presence of this IR peaks indicates that the NVP was present in all hybrids. The peaks between 3295 $\mathrm{cm}^{-1}$ to $3188 \mathrm{~cm}^{-1}$ are related to the $\mathrm{N}-\mathrm{H}$ and C-N stretch of seven membered ring of NVP, however, they not showed an apparent presence in the hybrids [38].

The spectra of the PCL/SiO $/ 2 / \mathrm{NVP} 10 \% \mathrm{w} / \mathrm{w}$ and PCL/NVP $10 \% \mathrm{w} / \mathrm{w}$ systems are very similar, as both presented strong stretching peak in the $1600 \mathrm{~cm}^{-1}$ region, it is characteristic of C-O stretching vibration of NVP cyclic amide [24] [38]. The spectra of the $\mathrm{PCL} / \mathrm{TiO}_{2} / \mathrm{NVP} 10 \% \mathrm{w} / \mathrm{w}$ and PCL/ViscogelS7/NVP $10 \%$ systems did not show this more intense peak. Besides, the $\mathrm{PCL} / \mathrm{SiO}_{2} / \mathrm{NVP}$ system showed more intense peaks at $1581 \mathrm{~cm}^{-1}$ than the other systems. Hence, this system can be characterized as having a strong interaction among PCL, $\mathrm{SiO}_{2}$ nanoparticles and NVP. 

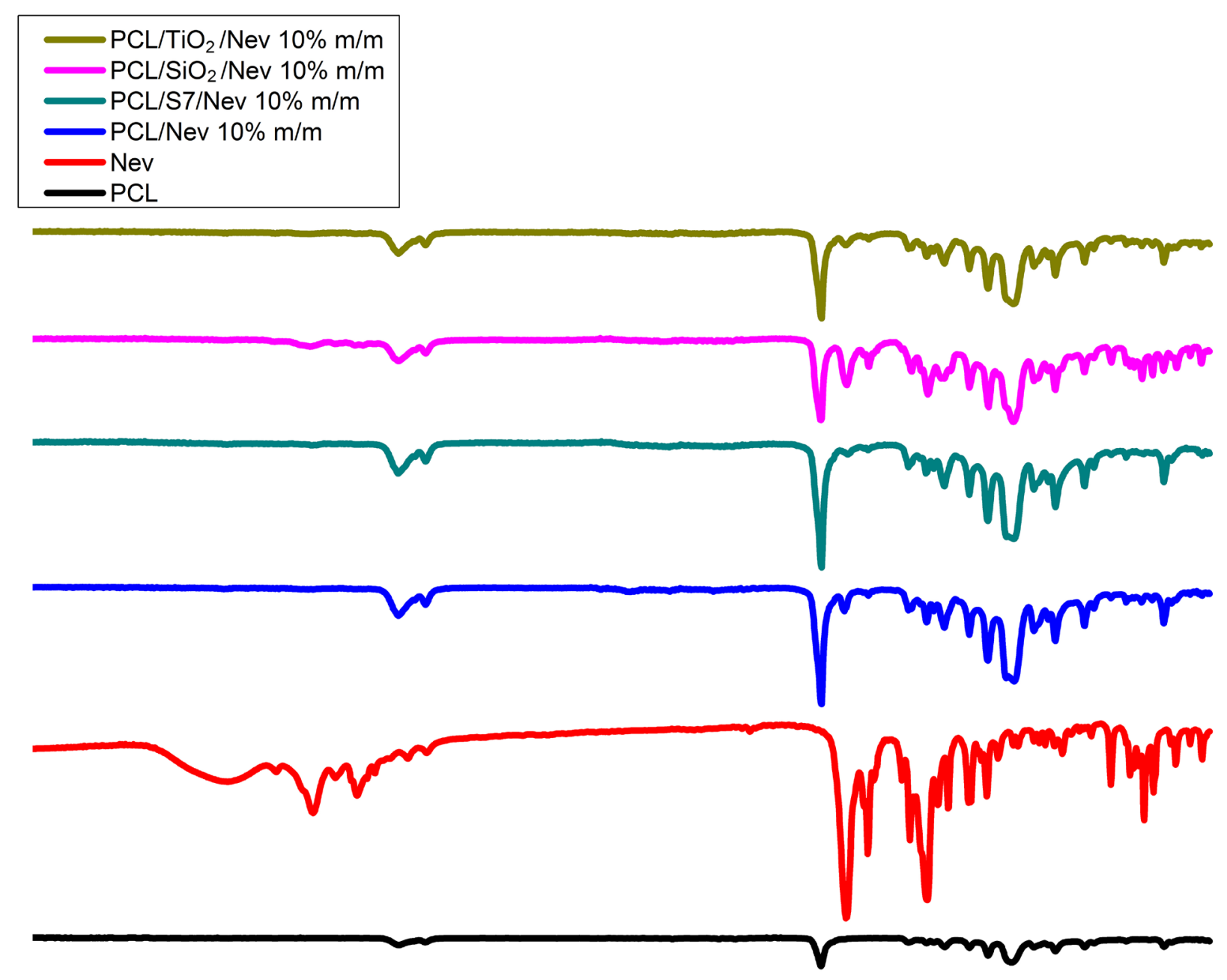

\begin{tabular}{cc|c|c|c|c|cc|}
\hline & 1 & 1 & 1 & 1 & 1 & 1 & 1 \\
4000 & 3500 & 3000 & 2500 & 2000 & 1500 & 1000 & 500 \\
& & Wavelength $\left(\mathrm{cm}^{-1}\right)$ &
\end{tabular}

Figure 4. FTIR spectra of PCL, NVP, PCL/NVP 10\% w/w, PCL/Viscogel S7/NVP 10\% w/w, PCL/SiO $/ 2 / \mathrm{NVP}_{10} \% \mathrm{w} / \mathrm{w}$ and PCL/TiO $/ 2$ NVP $10 \% \mathrm{w} / \mathrm{w}$ hybrid systems.

\subsection{Entrapment Efficiency}

The drug content was estimated to confirm that there is no degradation of the drug and expected amount of drug present in the system. The amount of NVP incorporated in each hybrid system is shown in Table 3. The concentrations were calculated from the equation obtained through linear regression analysis. The analyses were performed in triplicate.

According to Table 3, there was a little variation in the drug amount incorporated in different hybrids, but all systems presented close amounts. In relation to the procedure to prepare the films, there were not any components removed other than the solvent, consequently all samples presented the same drug loading. 


\subsection{In-Vitro Dissolution Studies}

An initial in-vitro dissolution studies was performed until 180 minutes, where all samples were segmented into $2 \times 2 \mathrm{~cm}^{2}$ pieces and analyzed in triplicate. Figure 5 shows the average of dissolved drug (\%) in the dissolution media for time zero, 15 minutes, 30 minutes, 45 minutes, 1 hour, 2 hours and 3 hours.

The release profile of PCL/NVP 10\% w/w, PCL/Viscogel S7/NVP 10\% w/w, PCL/ $\mathrm{SiO}_{2} / \mathrm{NVP} 10 \% \mathrm{w} / \mathrm{w}$ and $\mathrm{PCL} / \mathrm{TiO}_{2} / \mathrm{NVP} 10 \% \mathrm{w} / \mathrm{w}$ showed that the dissolved drug amounts were $28 \% \pm 0.4 \%, 24 \% \pm 0.24 \%, 8.3 \% \pm 0.3 \%$ and $24.5 \% \pm 0.45 \%$ (Figure 5 ). The statistical analysis showed that there were no significant differences in the release profiles $(\mathrm{P}<0.05)$.

In this study, NMR relaxometry measurements were performed to study the mobility of PCL macromolecules and of the drug, helping to make inferences about their confinement level inside the hybrids. It was conclude that the strength of the interaction between PCL, nanoparticles and NVP depends on the nanoparticle type (Viscogel S7, $\mathrm{SiO}_{2}$ or $\mathrm{TiO}_{2}$ ), which can have a direct influence on the NVP release.

In PCL/NVP hybrid, the NMR study indicated that the NVP molecules were better

Table 3. Amount of NVP $\left(\mathrm{mg} / \mathrm{cm}^{2}\right)$ in the hybrid systems.

\begin{tabular}{cc}
\hline Samples & $\mathrm{NVP}\left(\mathrm{mg} / \mathrm{cm}^{2}\right)$ \\
\hline $\mathrm{PCL} / \mathrm{NVP} 10 \% \mathrm{w} / \mathrm{w}$ & $1.37 \pm 0.02$ \\
$\mathrm{PCL} / \mathrm{S} 7 / \mathrm{NVP} 10 \% \mathrm{w} / \mathrm{w}$ & $1.43 \pm 0.02$ \\
$\mathrm{PCL} / \mathrm{SiO}_{2} / \mathrm{NVP} 10 \% \mathrm{w} / \mathrm{w}$ & $1.48 \pm 0.03$ \\
$\mathrm{PCL} / \mathrm{TiO}_{2} / \mathrm{NVP} 10 \% \mathrm{w} / \mathrm{w}$ & $1.52 \pm 0.01$ \\
\hline
\end{tabular}

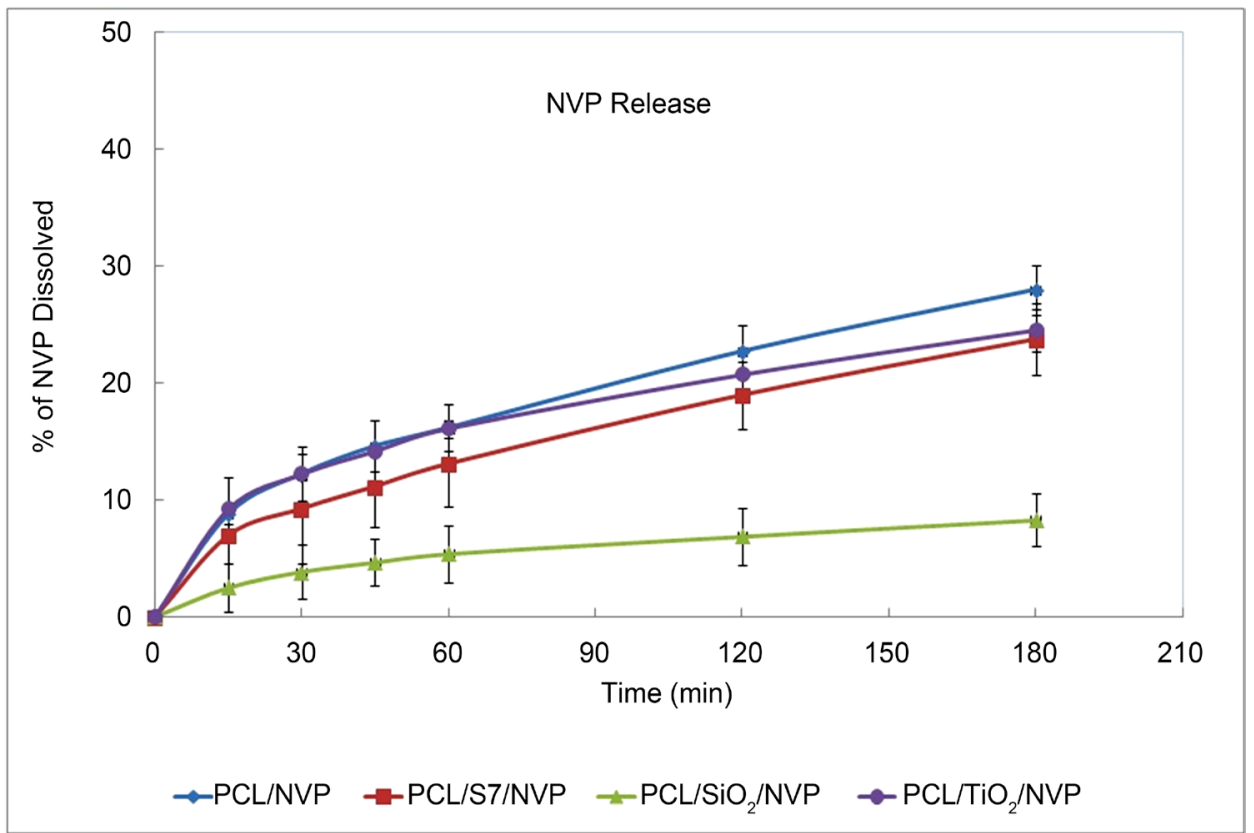

Figure 5. Average of dissolved drug (\%) in the dissolution media after $180 \mathrm{~min}$. 
distributed in the flexible-amorphous part of the PCL [21]. Probably, the amount of drug released, $28 \% \pm 0.4 \%$ of NVP, can be attributed to the drug molecules presents in the flexible-amorphous part of PCL. Consequently, the remaining amount of the NVP that was trapped in the rigid crystallites and "rigid-amorphous" region, hindered the drug release (Figure 3).

In the PCL/ViscogelS7/NVP system, the NVP molecules can modify the polymer arrangement around the S7 clay [21]. Therefore, the clay effect in modifying the drug's release was hardly noticed and probably the amount of drug released, around $24 \% \pm$ $0.24 \%$ of NVP, can also be attributed to the drug molecules presents in the flexible-amorphous part, as the PCL/NVP hybrid system. In the PCL/TiO $/ 2$ NVP, the concomitant introduction of the nanoparticles and NVP did not present a major change in the polymeric system [21]. Then, the addition of $\mathrm{TiO}_{2}$ did not show a significant effect on the NVP releasing and also the amount of drug released, around $24.5 \% \pm 0.45 \%$ of NVP, can be attributed to the drug molecules presents in the flexible-amorphous part, as the other hybrids systems.

The introduction of $\mathrm{SiO}_{2}$ nanoparticles affected the molecular motions of the PCL chains; however, the NVP insertion did not show a major change in the molecular dynamics of $\mathrm{PCL} / \mathrm{SiO}_{2}$ hybrid [21]. Besides that, the FTIR and XRD results showed that there was a strong interaction between NVP and $\mathrm{PCL} / \mathrm{SiO}_{2}$ hybrid system, verified by the appearance of bands in the FTIR spectrum and by the increase of PCL crystallinity in XRD. Probably, these interactions of NVP and $\mathrm{PCL} / \mathrm{SiO}_{2}$ hybrid may have favored the drug distribution in the crystalline, "rigid-amorphous", and even in the flexibleamorphous region, decreased the amount of drug released, around $8.3 \% \pm 0.3 \%$ of NVP. The NVP released can be attributed to the drug molecules presents in the flexible-amorphous part.

\subsection{Drug Release Kinetics}

Several methods have been used to indicate drug-release kinetics. These methods can be classified into several categories: statistical methods, methods independent of mathematical models, and methods dependent on mathematical models. The application of those models was performed to indicate possible release kinetics of the drug from the polymer matrix. The results obtained in the dissolution test can be interpreted using general equations which mathematically describe the dissolution curve on the basis of some parameters related to the dosage form. One criterion used to select the best model is the correlation coefficient $(r)$ [29] [39].

The mathematical models used in this study were the zero-order, first-order, Higuchi and Hixson-Crowell, to establish the most probable release kinetics of NVP from the PCL nanocomposites developed. The correlation coefficient $(r)$ values obtained are shown in Table 4. The Higuchi model showed the highest value of $(r)$ for the PCL/NVP $(r=0.9913), \mathrm{PCL} / \mathrm{ViscogelS} 7 / \mathrm{NVP}(r=0.9935), \mathrm{PCL} / \mathrm{SiO}_{2} / \mathrm{NVP}(r=0.9929)$ and PCL/ $\mathrm{TiO}_{2} / \mathrm{NVP}(r=0.9927)$ systems, indicating that the NVP release occurred according to the Higuchi model. 
As shown in Figure 6, the Higuchi equation plot presented good linearity, indicating the release of drug from matrix as the square root of a time-dependent process based on Fickian diffusion.

The Higuchi model describes the drug release mechanism as a diffusion process based on Fick's law, which depends on the square root of time. This means that the amount of drug released decreases with time of exposure to the dissolution medium. The reason for this is that the drug is released initially from the surface region, which is the shortest diffusion path, but as the dissolution progresses, the area of the drug exposed to the dissolution medium decreases [6] [40]. When the drug content in the surface runs out, probably, the next layer of the film begins to release the drug, which leads to an increase in the length of the diffusion path. Furthermore, the Higuchi model, besides Fickian diffusion, considers the influence of the polymer chains' relaxation on the drug release mechanism [41] [42].

Table 4. Release parameters of NVP sustained release films.

\begin{tabular}{|c|c|c|c|c|}
\hline \multirow{2}{*}{ Mathematical Models } & \multicolumn{4}{|c|}{ (r) Values } \\
\hline & PCL/NVP & $\mathrm{PCL} / \mathrm{S} 7 / \mathrm{NVP}$ & $\mathrm{PCL} / \mathrm{SiO}_{2} / \mathrm{NVP}$ & $\mathrm{PCL} / \mathrm{TiO}_{2} / \mathrm{NVP}$ \\
\hline Zero-Order & 0.9101 & 0.9063 & 0.8704 & 0.8831 \\
\hline First-Order & 0.86970 & 0.9052 & 0.8067 & 0.8103 \\
\hline Higuchi & 0.9913 & 0.9935 & 0.9927 & 0.9929 \\
\hline Hixson-Crowell & 0.8574 & 0.8967 & 0.7939 & 0.8066 \\
\hline
\end{tabular}

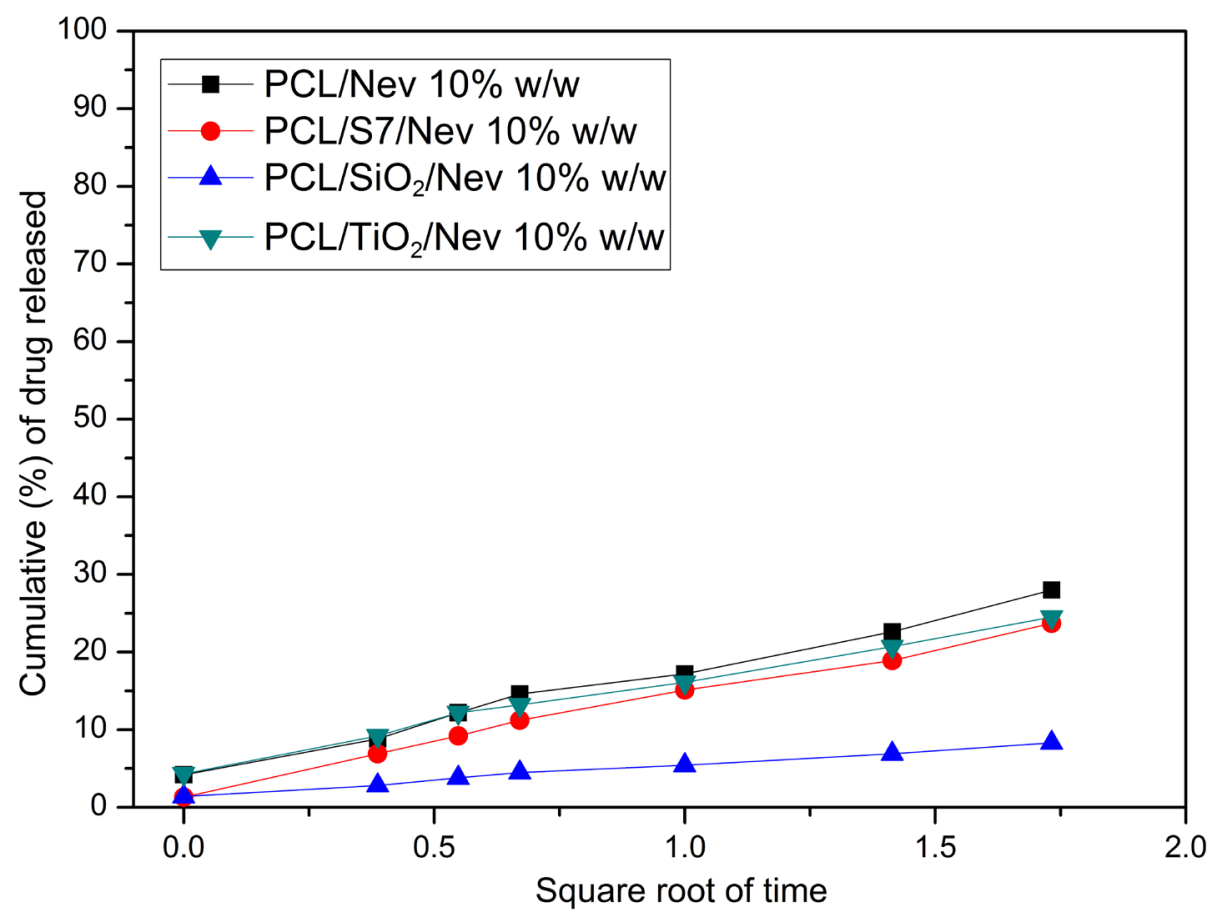

Figure 6. The cumulative amount (\%) of drug released in the dissolution media according the Higuchi model. 
All the hybrid systems developed provided a sustained release of NVP and the drug release is dependent on the diffusion of NVP molecules through the PCL matrix [6]. The PCL promotes the release of liphophilic drug, as NVP, by diffusion mechanisms' from its amorphous region, as liphophilic drug are usually uniformly distributed in the PCL matrix. In the case of diffusion, the drug release rate can be affected by the formation of pores, swelling of the polymer or by molecular interactions between the drug and polymer [43]. In the hybrids systems, such as PCL/NVP, PCL/S7/NVP and PCL/ $\mathrm{TiO}_{2} / \mathrm{NVP}$, the largest contribution to the release of NVP were the molecular interactions between the drug and PCL chains, since the amount of drug released was similar in these hybrids. It is possible to infer that in the $\mathrm{PCL} / \mathrm{SiO}_{2} / \mathrm{NVP}$ system, the $\mathrm{SiO}_{2}$ particles increased the molecular interactions between NVP and PCL chains, since this system released a lower amount of NVP, favoring its presence in the system. This fact may be related to the small diameter of silica nanoparticles, around $12 \mathrm{~nm}$, which have a high ratio surface/volume, increasing the interactions between NVP and PCL, and hindering the NVP release.

\section{Conclusions}

In this work, it was possible to produce PCL hybrids systems with NVP and different types of nanoparticles, $\mathrm{S} 7$ clay, $\mathrm{SiO}_{2}$ and $\mathrm{TiO}_{2}$, by solvent cast technique. Although, this technique is not commercially attractive and has exhibited severe limits to nanofiller levels, it's still possible to develop a homogenous system, with nanoparticles effectively dispersed and it is an easy way to produce polymer films. The drug introductions in polymeric films are preferred due to their slow degradation and large surface area. Furthermore, several studies have demonstrated their efficacy for long-term drug release and therapeutic effects [28].

The XRD analysis showed that the PCL crystallization was affected with introduction of nanoparticles and NVP, modifying the semi-crystalline structure of PCL and reducing the crystallinity. The low field NMR showed that when nanoparticles and NVP were added, the $\mathrm{T}_{1} \mathrm{H}$ values increased, for PCL, PCL/S7, PCL/SiO $\mathrm{S}_{2}$ and $\mathrm{PCL} / \mathrm{TiO} \mathrm{O}_{2}$ hybrids, suggesting that its addition produced a new material, with less molecular mobility, except for PCL/S7/NVP, which showed a decreased in $\mathrm{T}_{1} \mathrm{H}$ value, indicating the drug introduction caused a compensatory effect in the presence of clay. In addition, NMR showed the presence of three well defined domains, indicating three distinct environments: i) rigid crystallites, ii) a "rigid amorphous" region and iii) a flexible-amorphous region. The hybrids developed with clay and silica nanoparticles presented two domains, indicating two distinct environments, with different molecular motions. The introduction of $\mathrm{TiO}_{2}$ nanoparticles did not alter the molecular dynamics of PCL. The NVP insertion in the PCL/S7 hybrid system presented one domain, indicating an environment with a single molecular motion. In the $\mathrm{PCL} / \mathrm{SiO}_{2}$ hybrid, the introduction of NVP did not alter the two domains developed, which suggested two protons environments and the $\mathrm{PCL} / \mathrm{TiO}_{2} / \mathrm{NVP}$ hybrid also presented three well defined domains, very similar to the PCL pattern, indicating that the drug had less influence on the dynamics 
of these hybrids.

The FTIR analysis showed a strong interaction among PCL, $\mathrm{SiO}_{2}$ nanoparticles and NVP. The NVP entrapment efficiency was similar for all the systems. The in-vitro dissolution test showed no statistical differences among the amount of NVP released from hybrids. Probably, the amount of NVP released could be attributed to the drug molecules present in the flexible-amorphous part of PCL. Higuchi's model was the mathematical model chosen to treat the release data, since this model presented the highest $r$ value. All the systems showed decreasing NVP release with time, and the drug release probably occurred by diffusion through the matrix pores. So, the materials studied here can be used for sustained release of NVP.

It is desirable to have a controlled or sustained release system of NVP that could improve patient compliance, reduce the side effects and increase the therapeutic efficacy.

\section{Acknowledgements}

This work was supported by CAPES and CNPQ, Brazil.

\section{References}

[1] Arslan, M., Tasdelen, M.A., Uyar, T. and Yagci, Y. (2015) Poly(Epsilon Caprolactone)/Clay Nanocomposites via Host-Guest Chemistry. European Polymer Journal, 71, 259-267. http://dx.doi.org/10.1016/j.eurpolymj.2015.08.006

[2] Yan, L. and Chen, X. (2013) Nanocrystalline Materials. 2rd Edition, Elsevier, Amsterdam, 221-268.

[3] Mclauchlin, A.R. and Thomas, N.L. (2012) Biodegradable Polymer Nanocomposites. In: Advances in Polymer Nanocomposites. Types and Applications, 398-430. http://dx.doi.org/10.1533/9780857096241.2.398

[4] Dornelas, C.B., Silva, A.M., Dantas, C.B., Rodrigues, C.R., Coutinho, S.S., Sathler, P.C., Castro, H.C., Dias, L.R., Sousa, V.P. and Cabral, L.M. (2011) Preparation and Evaluation of a New Nano Pharmaceutical Excipients and Drug Delivery System Based in Polyvinylpyrrolidone and Silicate. Journal of Pharmacy and Pharmaceutical Sciences, 14, 17-35. http://dx.doi.org/10.18433/J3HC72

[5] Rodrigues, L.A.S., Figueiras, A., Veiga, F., Freitas, R.M., Cunha Nunes, L.C., Silva Filho, E.C. and Leite, C.M.S. (2013) The Systems Containing Clays Minerals from Modified Drug Release: A Review. Colloids and Surfaces B: Biointerfaces, 103, 642-651. http://dx.doi.org/10.1016/j.colsurfb.2012.10.068

[6] Dash, T.K. and Konkimalla, B. (2012) Poly- $\varepsilon$-Caprolactone Based Formulations for Drug Delivery and Tissue Engineering: A Review. Journal of Controlled Release, 158, 15-33. http://dx.doi.org/10.1016/j.jconrel.2011.09.064

[7] Liu, M., Chen, L., Zhao, Y., Gan, L., Zhu, D., Xiong, W., Lv, Y., Xu, Z., Hao, Z. and Chen, L. (2012) Preparation, Characterization and Properties of Liposome-Loaded Polycaprolactone Microspheres as a Drug Delivery System. Colloids and Surfaces A: Physicochemical and Engineering Aspects, 395, 131-136. http://dx.doi.org/10.1016/j.colsurfa.2011.12.017

[8] Schäler, K., Ostas, E., Schröter, K., Thurn-Albrecht, T., Binder, W.H. and Saalwächter, K. (2011) Influence of Chain Topology on Polymer Dynamics and Crystallization. Investigation of Linear and Cyclic Poly( $\varepsilon$-Caprolactone)s by ${ }^{1} \mathrm{H}$ Solid-State NMR Methods. Macromolecules, 44, 2743-2754. http://dx.doi.org/10.1021/ma102838c 
[9] Pena, J.A., Gutiérrez, S.J., Villamil, J.C., Agudelo, N.A. and Pérez, L.D. (2016) Policaprolactone/Polyvinylpyrrolidone/Siloxane Hybrid Materials: Synthesis and in Vitro Delivery of Diclofenac and Biocompatibility with Periodontal Ligament Fibroblasts. Materials Science and Engineering. C, 58, 60-69. http://dx.doi.org/10.1016/j.msec.2015.08.007

[10] Viseras, C., Cerezo, P., Sanchez, R., Salcedo, I. and Aguzzi, C. (2010) Current Challenges in Clay Minerals for Drug Delivery. Applied Clay Science, 48, 291-295. http://dx.doi.org/10.1016/j.clay.2010.01.007

[11] Shi, R., Magaye, R., Castranova, V. and Zhao, J. (2013) Titanium Dioxide Nanoparticles: A Review of Current Toxicological Data. Particle and Fibre Toxicology, 10, 15. http://dx.doi.org/10.1186/1743-8977-10-15

[12] Moosavi, M.A. and Rahmati, M. (2016) Titanium Dioxide $\left(\mathrm{TiO}_{2}\right)$ Nanostructures as an Ideal Tumor-Targeted Drug Delivery System. Austin Therapeutics, 2, 1016.

[13] Barbé, C., Bartlett, J., Kong, L., Finnie, K., Lin, H.Q., Larkin, M., Calleja, S., Bush, A. and Calleja, G. (2004) Silica Particles: A Novel Drug-Delivery System. Advanced Materials, 16, 1959-1966. http://dx.doi.org/10.1002/adma.200400771

[14] Catauro, M., Bollino, F., Papale, F., Piccolella, S. and Pacifico, S. (2016) Sol-Gel Synthesis and Characterization of $\mathrm{SiO}_{2} / \mathrm{PCL}$ Hybrid Materials Containing Quercetin as New Materials for Antioxidant Implants. Materials Science and Engineering. C, 58, 945-952. http://dx.doi.org/10.1016/j.msec.2015.09.054

[15] Jindal, N. and Mehta, S.K. (2015) Nevirapine Loaded Poloxamer 407/Pluronic P123 Mixed Micelles: Optimization of Formulation and in Vitro Evaluation. Colloids and Surfaces B: Biointerfaces, 129, 100-106. http://dx.doi.org/10.1016/j.colsurfb.2015.03.030

[16] Kuo, Y.-C. and Chung, J.-F. (2011) Physicochemical Properties of Nevirapine-Loaded Solid Lipid Nanoparticles and Nanostructured Lipid Carriers. Colloids and Surfaces B: Biointerfaces, 83, 299-306. http://dx.doi.org/10.1016/j.colsurfb.2010.11.037

[17] Stieger, N., Caira, M.R., Liebenberg, W., Tiedt, L.R., Wessels, J.C. and Villiers, M.M. (2010) Influence of the Composition of Water/Ethanol Mixtures on the Solubility and Recrystallization of Nevirapine. Crystal Growth \& Design, 10, 3859-3868.

http://dx.doi.org/10.1021/cg901501d

[18] Caxias, U., Antunes, A.M.M., Marinho, A.T., Godinho, A.L.A., Grilo, N.M., Marques, M.M., Oliveira, M.C., Branco, T., Monteiro, E.C. and Pereira, S.A. (2012) Evidence for Nevirapine Bioactivation in Man: Searching for the First Step in the Mechanism of Nevirapine Toxicity. Toxicology, 301, 33-39. http://dx.doi.org/10.1016/j.tox.2012.06.013

[19] Monteiro, M.S.S.B., Rodrigues, C.L., Neto, R.C. and Tavares, M.I.B. (2012) The Structure of Polycaprolactone-Clay Nanocomposites Investigated by ${ }^{1} \mathrm{H}$ NMR Relaxometry. Journal of Nanoscience and Nanotechonology, 12, 7307-7313. http://dx.doi.org/10.1166/jnn.2012.6431

[20] Monteiro, M.S.S.B., Neto, R.C., Souza, I.C.S., Silva, E.O. and Tavares, M.I.B. (2012) Inorganic-Organic Hybrids Based on Poly( $\varepsilon$-Caprolactone) and Silica Oxide and Characterization by Relaxometry Applying Low-Field NMR. Materials Research, 15, 825-832. http://dx.doi.org/10.1590/S1516-14392012005000121

[21] Monteiro, M.S.S.B., Chávez, F.V., Sebastião, P.J. and Tavares, M.I.B. (2013) ${ }^{1} \mathrm{H}$ NMR Relaxometry and X-Ray Study of PCL/Nevirapine Hybrids. Polymer Testing, 32, 553-566. http://dx.doi.org/10.1016/j.polymertesting.2013.01.016

[22] Sebastião, P.J., Monteiro, M.S.S.B., Brito, L.M., Rodrigues, E., Chávez, F. and Tavares, M.I.B. (2016) Conventional and Fast Field Cycling Relaxometry Study on the Molecular Dynamics in Polymer Nanocomposites for Use as Drug Delivery System. Journal of Nanoscience and Nanotechnology, 16, 7539-7545. http://dx.doi.org/10.1166/jnn.2016.12476 
[23] Wu, T.M., Cheng, J.-C. and Yan, M.-C. (2003) Crystallization and Thermoelectric Behavior of Conductive-Filler-Filled Poly( $\varepsilon$-Caprolactone)/Poly(Vinylbutyral)/Montmorillonite Nanocompostes. Polymer, 44, 2553-2562. http://dx.doi.org/10.1016/S0032-3861(03)00106-X

[24] Ayala, G.G., Pace, E.D., Laurienzo, P., Pantalena, D., Somma, E. and Nobila, M.R. (2009) Poly( $\varepsilon$-Caprolactone) Modified by Functional Groups: Preparation, and Chemical-Physical Investigation. European Polymer Journal, 45, 3217-3229.

http://dx.doi.org/10.1016/j.eurpolymj.2009.07.021

[25] Sarkar, M., Khandavilli, S. and Panchagnula, R. (2006) Development and Validation of RPHPLC and Ultraviolet Spectrophotometric Methods of Analysis for the Quantitative Estimation of Antiretroviral Drugs in Pharmaceutical Dosage Forms. Journal of Chromatography B, 830, 349-354. http://dx.doi.org/10.1016/j.jchromb.2005.11.014

[26] Grangeiro Jr., S., Strattmann, R.R., Albuquerque, M.M., Araújo, A.A.S., Matos, J.R. and Rolim Neto, P.J. (2006) In Vitro Evaluation of Dissolution Profiles and Thermal Properties of Some Commercial Formulations of Nevirapine Tablets. Acta Farmacéutica Bonaerense, $25,76-82$.

[27] Sarkar, M., Perumal, O.P. and Panchagnula, R. (2008) Solid-State Characterization of Nevirapine. Indian Journal of Pharmaceutical Sciences, 70, 619-630.

http://dx.doi.org/10.4103/0250-474X.45401

[28] Dash, S., Murthy, P.N, Nath, L. and Chowdhury, P. (2010) Kinetic Modeling on Drug Release from Controlled Drug Delivery Systems. Acta Poloniae Pharmaceutica, 67, 217-223.

[29] Costa, P.J.C. (2002) Avaliação in vitro da lioequivalência de formulações farmacêuticas. Revista Brasileira de Ciências Farmacêuticas, 38, 141-153. http://dx.doi.org/10.1590/s1516-93322002000200003

[30] Wiens, M., Elkhooly, T.A., Schröder, H.C., Mohamed, T.H.A. and Müller, W.E.G. (2014) Characterization and Osteogenic Activity of a Silicatein/Biosilica-Coated Chitosan-GraftPolycaprolactone. Acta Biomaterialia, 10, 4456-4464. http://dx.doi.org/10.1016/j.actbio.2014.06.036

[31] Sahoo, S., Sasmal, A., Nanda, R., Phani, A.R. and Nayak, P.L. (2010) Synthesis of ChitosanPolycaprolactone Blend for Control Delivery of Ofloxacin Drug. Carbohydrate Polymers, 79, 106-113. http://dx.doi.org/10.1016/j.carbpol.2009.07.042

[32] Sanganwar, G.P., Sathigari, S., Babu, R.J. and Gupta, R.B. (2010) Simultaneous Production and Co-Mixing of Microparticles of Nevirapine with Excipients by Supercritical Antisolvent Method for Dissolution Enhancement. European Journal of Pharmaceutical Sciences, 39, 164-174. http://dx.doi.org/10.1016/j.ejps.2009.11.011

[33] Zou, H., Wi, S. and Shen, J. (2008) Polymer/Silica Nanocomposites: Preparation, Characterization, Properties and Applications. Chemical Reviews, 108, 3893-3957. http://dx.doi.org/10.1021/cr068035q

[34] Passos, A.A., Tavares, M.I.B., Neto, R.C.P. and Ferreira, A.G. (2012) The Use of Solid State NMR to Evaluate EVA/Silica Films. Journal of Nano Research, 18-19, 219-226. http://dx.doi.org/10.4028/www.scientific.net/JNanoR.18-19.219

[35] Kango, S., Kalia, S., Celli, A., Njuguna, J., Habibi, Y. and Kumar, R. (2013) Surface Modification of Inorganic Nanoparticles for Development of Organic-Inorganic Nanocomposites-A Review. Progress in Polymer Science, 38, 1232-1261. http://dx.doi.org/10.1016/j.progpolymsci.2013.02.003

[36] Wu, T., Xie, T. and Yang, G. (2009) Preparation and Characterization of Poly(c-Caprolactone)/Na ${ }^{+}-\mathrm{MMT}$ Nanocomposites. Applied Clay Science, 45, 105-110. http://dx.doi.org/10.1016/j.clay.2009.02.009 
[37] Elzein, T., Nasser, M.E., Delaite, C., Bistac, S. and Dumas, P. (2004) FTIR Study of Polycaprolactone Chain Organization at Interfaces. Journal of Colloid and Interface Science, 273, 381-387. http://dx.doi.org/10.1016/j.jcis.2004.02.001

[38] Pereira, B.G., Fonte-Boa, F.D., Resende, J.A.L.C., Pinheiro, C.B., Fernandes, N.G., Yoshida, M.I. and Vianna-Soares, C.D. (2007) Pseudopolymorphs and Intrinsic Dissolution of Nevirapine. Crystal Growth \& Design, 7, 2016-2023. http://dx.doi.org/10.1021/cg0704495

[39] Shoaib, M.H., Tazeen, J., Merchant, H.Á. and Yousuf, R.I. (2006) Evaluation of Drug Release Kinetics from Ibuprofen Matrix Tablets Using HPMC. Pakistan Journal of Pharmaceutical Science, 19, 119-124.

[40] Paul, D.R. (2011) Elaborations on the Higuchi Model for Drug Delivery. International Journal of Pharmaceutics, 418, 13-17. http://dx.doi.org/10.1016/j.ijpharm.2010.10.037

[41] Petropoulos, J.H., Papadokostaki, K.G. and Sanopoulou, M. (2012) Higuchi's Equation and beyond: Overview of the Formulation and Application of a Generalized Model of Drug Release from Polymeric Matrices. International Journal of Pharmaceutics, 437, 178-191. http://dx.doi.org/10.1016/j.ijpharm.2012.08.012

[42] Siepmann, J. and Peppas, N.A. (2011) Higuchi Equation: Derivation, Applications, Use and Misuse. International Journal of Pharmaceutics, 418, 6-12. http://dx.doi.org/10.1016/j.ijpharm.2011.03.051

[43] Badder, R.A. and Putnam, D.A. (2014) Engineering Polymer Systems for Improved Drug Delivery. John Willey \& Sons, 496 p. for you:

Accepting pre-submission inquiries through Email, Facebook, LinkedIn, Twitter, etc. A wide selection of journals (inclusive of 9 subjects, more than 200 journals)

Providing 24-hour high-quality service

User-friendly online submission system

Fair and swift peer-review system

Efficient typesetting and proofreading procedure

Display of the result of downloads and visits, as well as the number of cited articles

Maximum dissemination of your research work

Submit your manuscript at: http://papersubmission.scirp.org/

Or contact msa@scirp.org 